\title{
EL VOCAL-REPRESENTANTE DEL PROFESORADO OFICIAL DEL ESTADO EN LOS TRIBUNALES DE OPOSICIONES Y CONCURSOS DE LA ADMINISTRACION LOCAL
}

352.082 .1

por

\section{José-María de Frutos Isabel}

Profesor Adjunto Numerario de Derecho administrativo en la Facultad de Derecho de la Universidad de Santiago

SUMARIO: I. INTRODUCCION.-II. LOS PRECEDENTES HISTORICOS: 1. LA LEY MUNICIPAL De 1870. 2. LA LEY PROVINCIAL DE 1882. 3. Los Reglamentos de Secretarios de Ayuntamiento y de ContaDORES DE Fondos provinciales $Y$ locales. 4. El Estatuto municiPAL DE 1924. 5. El ESTATUTO PROVINCIAL DE 1925. 6. LA LEX MUNICIPAL DE 1935.-III. LA REGULACION ACTUAL.-IV. EL PROFESORADO OFICIAL DEL ESTADO.-V. LA RESOLUCION DE LA SUBSECRETARIA DEL MINISTERIO DE EDUCACION Y CIENCIA DE 20 DE JULIO DE 1971.-VI. LA COMPETENCIA NORMATIVA . EN LA FUNCION PUBLICA LOCAL.-VII. LA EQUIPARACION DE LOS FUNCIONARIOS LOCALES A LOS DE LA ADMINISTRACION DEL ESTADO.-VIII. EL PRINCIPIO DE ESPECIALIDAD DE LOS TRIBUNALES.-IX. CONCLUSIONES.

\section{INTRODUCCION}

La continuidad casi periódica con que hemos intervenido en diferentes Tribunales juzgadores de oposiciones y concursos para la provisión de plazas de funcionarios de Administración local, tanto 
de Diputaciones como de Ayuntamientos, en el ámbito del Distrito universitario donde desarrollamos nuestra función docente y la lectura diaria del Boletín Oficial del Estado, donde con frecuencia casi cotidiana se puede ver la composición de los Tribunales a que anteriormente aludimos, nos ha hecho meditar sobre quién es y quién debe ser el vocal representante del Profesorado oficial del Estado, cuál es su normativa reguladora y quién debe hacer su designación, todo ello con base en unos principios informadores determinantes de su razón de ser, dado que en Derecho no debe haber nada por arte de porque sí y todo debe estar incardinado en un proceso lógico y predeterminado por la norma jurídica como garantía de un recto y confiado quehacer.

La realidad del Boletín Oficial del Estado nos muestra cómo para unas mismas oposiciones o concursos, donde se exige una misma titulación, unas veces el representante del Profesorado oficial del Estado es un profesor universitario y otras veces de otros sectores docentes, y no sólo en distintos Ayuntamientos y Diputaciones, sino incluso en los mismos y para las mismas plazas (1).

Todo ello nos induce a ofrecer estas consideraciones, anticipadamente modestas por ser nuestras, en unión de unas conclusiones, que pretendemos hacer llegar a los órganos normativos de la Función Pública Local.

\section{LOS PRECEDENTES HISTORICOS}

\section{LA LEY MUNICIPAL DE 1870}

La Ley municipal de 20 de agosto de 1870 , modificada por la de 16 de diciembre de 1876 y que dio lugar al Texto refundido aprobado por Real Decreto de 2 de octubre de 1877, señaló en sus artículos 74 y 78 que era atribución exclusiva de los Ayuntamientos el nombramiento y separación de todos los empleados y dependientes pagados de los fondos municipales.

(1) En el Boletín Oficial del Estado de 5 de marzo de 1975, páginas 4583-4584, se publica el Tribunal juzgador de la oposición convocada para la provisión de una plaza de oficial de la Escala Técnico-Administrativa del Ayuntamiento de Silleda (Pontevedra), y en él aparecen como representantes del Profesorado oficial del Estado, titular y suplente, dos profesores de Lengua y Literatura Española e Inglés, respectivamente, del Instituto Nacional de Bachillerato de La Estrada, en la misma Provincia. Esa misma plaza un año antes fue convocada a oposición y juzgada por un Tribunal, en el que los representantes del Profesorado oficial del Estado fueron profesores numerarios de la Facultad de Derecho de la Universidad de Santiago. 
Ahora bien, como el artículo 123 señalaba que para ser Secretario se necesitaba «poseer los conocimientos de la instrucción primaria", lógico es pensar que para los demás funcionarios, empleados o dependientes no se exigieran mayores requisitos culturales. Pero como tenían potestad reglamentaria y consecuentemente podían emanar reglamentos de funcionarios (2), lógico es deducir que en ellos se determinara cómo era su selección y cuál el procedimiento en todas sus fases, ante el silencio de la Ley.

\section{LA LEY PROVINCIAL DE 1882}

La Ley provincial de 29 de agosto de 1882 contiene preceptos semejantes a los señalados en la Ley municipal en los artículos 74 y 104. Pero por Real Decreto de 11 de diciembre de 1900 se aprueba el Reglamento de Secretarios de las Diputaciones (3) y en él encontramos el primer precedente de lo que hoy llamaríamos «representantes del Profesorado oficial del Estado", pues en el artículo 6. se determina que el título de aptitud exigido para ingresar en el Cuerpo de Secretarios se obtendrá mediante examen, ante un Tribunal, nombrado por el Ministro, que se compondrá, entre otros, de un catedrático de la Facultad de Derecho de la Universidad Central.

\section{Los Reglamentos de Secretarios de Ayuntamiento $Y$ DE CONTADORES DE Fondos PROVINCIALES Y LOCALES}

Como es sabido, por Real Decreto de 14 de junio de 1905 se puso en vigor, con carácter provisional, el Reglamento de Secretarios de Ayuntamiento. A su tenor (artículo 14), todos los aspirantes que desearen obtener títulos de aptitud para Secretarios de Ayuntamiento en Municipios de 2.000 a 15.000 habitantes, exceptuados los de capitales de Provincia, harían sus exámenes ante los Tribunales que se constituirían, en el último mes de cada año, en todas las capitales de Provincia. Los que desearen obtener título de apti-

(2) GiméneZ Valdrvieso, Tomás: Ley municipal de 1877 comentada y anotada, Valencia, 1910, página 208, refiere que Madrid y Valencia tienen para sus Secretarios y demás empleados Reglamentos completos.

(3) Por otro Decreto de la misma fecha se aprueba el Reglamento de Contadores de Fondos provinciales y municipales. 
tud para Secretario de Ayuntamiento en Municipio mayor de 15.000 habitantes o en capital de Provincia, habrían de hacerlo ante Tribunal superior de Madrid.

Pues bien, los Tribunales de Provincias, si fuere de capital que tuviere Universidad, habrían de estar presididos por el Rector de la misma o un catedrático en quien delegue, e integrado, entre otros, por otro catedrático de Facultad de Derecho, designado por el Claustro, y el Director del Instituto (4).

El Tribunal superior de Madrid, presidido por el Director de Administración (hoy diríamos el Director general de Administración Local), estaba integrado, entre otros, por el catedrático de Derecho administrativo de la Universidad Central, y un catedrático de Francés, nombrado por el Ministro de Instrucción Pública.

Ello nos quiere decir que en los Tribunales de Provincias habría, en algunos casos (capitales de Provincia con Universidad), tres miembros de los que hoy llamariamos Profesorado oficial del Estado; en otros, uno; y en el Tribunal superior de Madrid, dos.

Pero he aquí lo importante: podemos apreciar en ello un principio de generalidad (el Rector o catedrático en quien delegue; el Director del Instituto), un principio de especialidad (catedrático de Facultad de Derecho) y un principio de concreción (catedrático de Derecho administrativo, catedrático de Francés).

Si pasamos al Reglamento orgánico del Cuerpo de Secretarios de Ayuntamiento de 1916, aprobado con carácter provisional por el Real Decreto de 23 de agosto, apreciamos que se mantiene un sistema semejante de Tribunales de Provincias y Tribunal superior de Madrid, pero distinto. El Tribunal de Provincias estará presidido por «el Rector de la Universidad, si lo hubiere, o de un catedrático de la Facultad de Derecho designado por el Claustro, o del Director del Instituto» e integrado, entre otros, por «un profesor mercantil o de Matemáticas del Instituto, designado por el Claustro de éste». Y el Tribunal superior de Madrid, presidido por el Rector de la Universidad, estaba integrado, además y entre otros, por el catedrático de Derecho administrativo de la misma Universidad, designado por el Rector; y por un catedrático de la Escuela de Comercio. Los principios a que antes hemos aludido juegan aquí de manera diferente.

(4) En las capitales donde no existía Universidad presidia el Tribunal el Presidente de la Diputación y era vocal un diputado provincial, designado por el Presidente, que tuviere el carácter de Letrado. 
En el Reglamento de Contadores de Fondos provinciales y municipales y Jefes de Sección de Examen de Cuentas y Presupuestos municipales de los Gobiernos de Provincia, aprobado por Real Decreto de 23 de agosto de 1916, se determina (artículo $8^{\circ}$ ) que para obtener certificado de aptitud de tales cargos se efectuarán en Madrid los oportunos exámenes ante un Tribunal del que formará parte, entre otros y como vocal, un catedrático de la Escuela Superior de Administración Mercantil de Madrid, designado por el Director de la misma. Este mismo precepto se repite en el artículo 8. del Reglamento de Contadores de Fondos de la Administración Local, aprobado por Real Decreto de 3 de abril de 1919, que deroga el anterior y da nueva denominación al Cuerpo. Hay, pues, un principio de especialidad respecto del Profesorado oficial del Estado, con terminología actual.

\section{El Estatuto municipal DE 1924}

Como es sabido, el Estatuto municipal, aprobado por Real Decreto-ley de 8 de marzo de 1924, abolió el sistema de los certificados de aptitud y estableció la oposición como forma de ingreso en los Cuerpos de Secretarios e Interventores y para los empleados administrativos municipales, y la oposición o concurso, según acordase la Corporación, para los funcionarios técnicos y titulados.

La oposición para Secretarios se verificará ante un Tribunal del que formarán parte, en la proporción que determine el Reglamento, catedráticos de Facultad de Derecho (artículo 232). Para los Interventores, de los Tribunales formarán parte catedráticos (artículo 241). Para los empleados municipales en general, en los Tribunales, sean juzgadores de oposición o concurso, ha de haber siempre representación de los Ayuntamientos, de los funcionarios y del Profesorado oficial del Estado (artículo 247). Vemos, pues, cómo la expresión "Profesorado oficial del Estado" o "representación del Profesorado oficial del Estado» aparece por primera vez en el Estatuto municipal, pero no podemos olvidar, y sobre ello volveremos después, que antes se ha dicho "catedráticos de Facultad de Derecho" (secretarios) y "catedráticos» (interventores) y se deja el término «Profesorado oficial del Estado» para los empleados administrativos en general.

Como el Estatuto se remite a un Reglamento posterior, éste, 
aprobado por Real Decreto de 23 de agosto de 1924, viene a desarrollar aquél, resumidamente, en la forma siguiente:

Para Secretarios.-Los exámenes para ingreso en el Cuerpo se celebrarán en Madrid o en las capitales de Distrito universitario. Para las que se celebraran en Madrid, formaba parte del Tribunal, como vocal, un catedrático de Facultad de Derecho, designado por el Rector de la Universidad Central, y cuando los exámenes fueren en una capital de Distrito universitario, el Tribunal estaba presidido por un catedrático de Derecho administrativo o político, designado por el Rector (artículo 10).

Para Interventores.-Sistema semejante al anterior. Para los exámenes en Madrid era vocal un catedrático de la Escuela Central de Estudios Mercantiles, designado por el Director de la misma, y para los exámenes en capitales de Distrito, el Tribunal lo constituirá un catedrático de Hacienda Pública, como presidente (artículo 65).

Para Depositarios.-El Real Decreto de 10 de junio de 1930 aprueba el Reglamento orgánico, primero en el tiempo, del Cuerpo de Depositarios de Fondos de la Administración Local y en él se determina (artículo 14) que para ingresar en dicho Cuerpo será preciso un título de aptitud, que sólo podrá obtenerse mediante examen público, a celebrar en Madrid, una vez al menos cada tres años y ante un Tribunal compuesto, entre otros, por «un catedrático o profesor de la Sección de Ciencias de los Institutos Nacionales de Segunda Enseñanza actualmente establecidos en esta Corte o de la Escuela Central de Estudios Mercantiles, designados por el Director del Instituto o de dicha Escuela».

Para empleados municipales en general.-El artículo 248 del Estatuto establecía como obligación de los Ayuntamientos formar reglamentos de funcionarios, que debían ser distintos para el personal técnico, el administrativo y el subalterno, y tendrán el carácter de Estatuto legal de los mismos. Tales reglamentos habrían de fijar, entre otras cosas, la manera de constituir los Tribunales, teniendo en cuenta las prescripciones del Estatuto y del Reglamento antes citado de 23 de agosto de 1924, el cual determina fundamentalmente (artículos 94 y 97) que el Ayuntamiento nombrará el Tribunal en las oposiciones o concursos de plazas de funcionarios técnicos 
o titulados y en las oposiciones de empleados administrativos municipales, añadiendo que en el Tribunal «la representación de funcionarios lo será de técnicos o titulares de la especialidad a que la vacante pertenezca». Con ello no sè alude para nada a cómo ha de ser la representación del Ayuntamiento y del Profesorado oficial del Estado. Por Real Orden de 14 de mayo de 1928 se aprueba el Reglamento de Funcionarios municipales para aquellos Ayuntamientos que no hayan cumplido la obligación de formarlo por sí mismos, conforme el artículo 248 del Estatuto, y en su artículo 15 se determina que «en los Tribunales que designen las Corporaciones ha de haber siempre representación de los Ayuntamientos, Profesorado oficial...», añadiendo: "en las localidades en que no haya posibilidad de constituir el Tribunal con las diversas representaciones citadas, los Gobernadores civiles resolverán designando funcionarios similares a los indicados».

\section{El Estatuto PRovincial de 1925}

El Estatuto aprobado por Real Decreto-ley de 20 de marzo de 1925 no contiene a este respecto innovación digna de mención con relación al Estatuto municipal y con referencia a los demás empleados de la Administración provincial (excluidos el Secretario, ya que establece la fusión de éstos con los de Ayuntamiento, y el Interventor, que debe pertenecer al Cuerpo de Interventores de la Administración Local) el artículo 153 reproduce casi literalmente el artículo 247 del Estatuto municipal. No obstante, el Reglamento de funcionarios y subalternos provinciales, aprobado por Real Decreto de 2 de noviembre de 1925, disiente de lo señalado en el Reglamento de 23 de agosto de 1924, pues los «abogados, archiveros, arquitectos, capellanes, ingenieros, veterinarios y demás técnicos», que según este último serían seleccionados por oposición o concurso, según lo determinare la Corporación, según aquél serán nombrados por concurso, y los médicos, practicantes y matronas, por oposición. Pero más importante, a los efectos de este trabajo, es lo dispuesto en el artículo 53 del referido Decreto de 1925, a saber:

«El ingreso en el Cuerpo administrativo será siempre por oposición y por la última categoría, ante Tribunal presidido por el de la Corporación o su delegado, y del que formen parte catedráticos del Estado...». 
En resumen, para el Estatuto provincial de 1925 la «representación del Profesorado oficial del Estado» son «catedráticos del Estado».

\section{LA LEY MUNICIPAL DE 1935}

La Base XXIII de la Ley municipal de 10 de julio de 1935, titulada «De los funcionarios municipales», tras clasificar a los funcionarios de Administración local en diferentes grupos y señalar que el nombramiento de todos los funcionarios compete a las respectivas Corporaciones y se efectuará siempre por oposición o concurso, establece en su apartado 13:

"Tales oposiciones y concursos serán juzgados por Tribunales y Comisiones exclusivamente técnicos, presididos por un representante de la Corporación interesada...».

Aprobado por Decreto de 31 de octubre de 1931 el texto articulado de esta Ley de Bases, su artículo 159 reproduce el transcrito apartado 13 y más adelante (artículo 172), al referirse a las oposiciones a Secretarios, establecerá que se celebrarán en Madrid o en las capitales de Distrito universitario, ante un Tribunal del que formarán parte, entre otros, "catedráticos de la Facultad de Derecho»; y en el artículo 181, relativo a Interventores, dirá que de los Tribunales formarán parte, entre otros, "catedráticos». De los demás funcionarios municipales no se hacen especificaciones concretas y se remite (artículo 187) al Reglamento de carácter general que dicte el Gobierno y a los especiales que mantengan o promulguen las respectivas Entidades municipales y que, como es sabido, no llegaron a emanarse. Por aplicación de la Disposición transitoria décima siguió rigiendo el Reglamento de 23 de agosto de 1924 y, en su caso, el de 14 de mayo de 1928.

\section{LA REGULACION ACTUAL}

La Ley de Bases de 17 de julio de 1945 dedica la Base LV a los funcionarios locales y al objeto que nos mueve no contiene ninguna referencia específica. Su Ley articulada, aprobada por Decreto de 24 de junio de 1955, les dedica el Título III del Libro III que, como es sabido, está desarrollado por el Reglamento de Funcionarios de 
la Administración Local de 30 de mayo de 1952. A su tenor tenemos que destacar:

a) Las oposiciones y concursos para la selección de funcionarios serán convocados por el órgano a quien corresponde otorgar el nombramiento. Los secretarios, interventores y depositarios de Administración Local y los directores de Bandas de Música civiles constituyen Cuerpos Nacionales, dependientes de la Dirección General de Administración Local, que es quien convoca las oposiciones para ingreso en dichos Cuerpos (artículo 322 de la Ley).

El nombramiento de los demás funcionarios será competencia de las respectivas Corporaciones, a través de sus pertinentes órganos, y se efectuará siempre por oposición o concurso, juzgados por Tribunales o Comisiones de carácter técnico-administrativo, que presidirá un representante de la Corporación interesada (artículo 323 de la Ley).

b) No se menciona expresamente, como ocurría en la legislación anterior, cuál ha de ser el profesor oficial del Estado o representante del Profesorado oficial del Estado que forme parte del Tribunal juzgador de las oposiciones a ingreso en los Cuerpos de Secretarios, Interventores y Depositarios de Administración Local, pues el artículo 191 del Reglamento se limita a decir que «los Tribunales serán presididos, sâlvo que asista el Director general de Administración Local, por el Director del Instituto de Estudios de Administración Local, y se constituirán en la forma y número que en cada caso, y atendiendo las circunstancias de la oposición y volumen de oposiciones, determine la Comisión Permanente de dicho Centro de Estudios».

No obstante, hay que tener en cuenta que conforme el artículo 72 del Reglamento provisional del Instituto de Estudios de Administración Local, aprobado por Decreto de 24 de junio de 1941, - su plantilla docente estará constituida:

«Hasta diez profesores titulares para los cursos profesionales, designados entre catedráticos de la Facultad de Derecho (en las materias jurídicas); profesores de las Escuelas de Ingenieros o Arquitectos (en materias de Urbanología), y profesores de la Escuela de Comercio (en materia de Contabilidad)»(5),

(5) En dicha fecha todavía no estaba creada la Facultad de Ciencias Políticas, Económicas y Comercialès, que surgió en 1943. 
y por tanto bien puede decirse que el Profesorado oficial del Estado está representado en los Tribunales mencionados, pues normalmente en las convocatorias de oposición suele establecer una de sus bases:

«Los ejercicios se celebrarán en el Instituto de Estudios de Administración Local, ante uno o más Tribunales, integrados por el Director general de Administración Local o el Director del Instituto, que presidirán por este orden, y por miembros pertenecientes al Instituto y a su Escuela Nacional de Administración y Estudios Urbanos hasta completar el número de...».

c) La oposición para ingreso en el Cuerpo Nacional de Directores de Bandas de Música civiles se celebrará en Madrid (artículo 214 del Reglamento) ante un Tribunal, del que será vocal

«un profesor de Composición o de Armonía del Real Conservatorio de Música y Declamación de Madrid, propuesto por el Director de dicho Centro».

d) Los demás funcionarios administrativos, los técnicos y los de servicios especiales serán nombrados, por las Corporaciones a que hayan de adscribirse, mediante concurso u oposición. En los Tribunales habrá siempre representación de las Corporaciones, de los funcionarios y del Profesorado oficial del Estado, así como, en su caso, de las profesiones respectivas (artículo 350, 1 y 2, de la Ley).

Este precepto genérico de la Ley aparece desarrollado en el Reglamento de Funcionarios de la forma siguiente:

Los Tribunales calificadores de oposiciones y concursos de los funcionarios administrativos (Oficial Mayor, jefes de Sección, jefes de Negociado, oficiales y auxiliares) estarán integrados en la siguiente forma: presidente, el de la Corporación o miembro de la . misma en quien delegue; vocales, un representante del Profesorado oficial, el Secretario de la Corporación, el representante que en su caso pueda designar la Dirección General de Administración Local y un funcionario administrativo que actuará de secretario. Cuando se trate de la provisión de plazas técnico-administrativas, formará parte del Tribunal el Jefe de la Abogacía del Estado en la Provincia o Abogado del Estado en quien delegue, y para las oposiciones. que se celebren en Madrid, lo designará el Director general de Administración Local. En. las poblaciones en que existan secciones del 
REVL-1975, núm. 187. FRUTOS ISABEL, JOSE MARIA DE. EL VOCAL-REPRESENTANTE DEL PR...

EL VOCAL-REPRESENTANTE OFICLAL EN LOS TRIBUNALES DE OPOSICIONES Y CONCURSOS

Instituto de Estudios de Administración Local corresponderá a este Centro designar el representante del Profesorado oficial (artículo 235).

Los Tribunales calificadores de los concursos u oposiciones para funcionarios técnicos estarán constituidos en la siguiente forma: presidente, el de la Corporación o un miembro de la misma en quien delegue; vocales, un representante del Profesorado oficial del Estado, etc. Los vocales habrán de poseer título oficial facultativo o superior en la especialidad (artículo 245).

Los Tribunales calificadores de oposiciones y concursos a funcionarios de servicios especiales estarán constituidos en la siguiente forma: presidente, el de la Corporación o un miembro electivo de la misma; vocales, el jefe o un funcionario técnico del servicio correspondiente a la especialidad, un representante del Profesorado oficial del Estado en materias afines a la función, y el representante de la Dirección General de Administración Local (artículo 251,1 ).

e) Los funcionarios subalternos serán nombrados por la Corporación mediante concurso, previo un examen de aptitud. El Tribunal que haya de juzgar la aptitud se constituirá con miembros y funcionarios de la Corporación (artículo 352, 1, de la Ley). Este Tribunal será designado por la Corporación y en él habrá, cuando menos, un representante de la misma y otro de los funcionarios.

Como resumen de todo ello puede concluirse lo siguiente:

Primero. Los Tribunales juzgadores de oposiciones y concursos de los funcionarios de Administración local, no pertenecientes a Cuerpos Nacionales, y con la sola excepción de los subalternos, no son nombrados por las Corporaciones, es decir, no constituye el nombramiento del Tribunal un acto administrativo municipal o provincial (6). Tales Tribunales o Comisiones no son nombrados, sino que resultan nombrados, bien por determinación legal y/o reglamentaria y a través de diversos actos de distinta procedencia, y ese resultado es el que hace público la Corporación, normalmente

(6) El Reglamento de Funcionarios es bien claro a este respecto: «Todo nombramiento en propiedad deberá ser conferido previa oposición o concurso juzgados por el Tribunal o Comisión calificadora reglamentariamente constituidos» (artículo 21.1).

"Los Tribunales y Comisiones calificadoras de oposiciones y concursos se cons. tituirán a tenor de lo dispuesto para cada grupo o categoría de funcionarios. Los Tribunales constituidos en las Corporaciones locales serán presididos por un representante de las mismas» (art. 26). 
el Alcalde, cuando se inserta en los Boletines Oficiales del Estado y/o de la Provincia, según proceda.

Segundo. El representante del Profesorado oficial del Estado ofrece manifestaciones diversas, pues fundadamente se deduce que lo hay en las oposiciones a Secretarios, Interventores y Depositarios; expresamente se determina quién ha de ser para los Directores de Bandas de Música civiles; se menciona sin ninguna concreción para los funcionarios administrativos; se requiere una titulación específica universitaria o técnica en la especialidad para los funcionarios técnicos, y ha de ser de materias afines a la función cuando se trate de funcionarios de servicios especiales.

Tercero. Se determinen o no las cualidades que deba tener el representante del Profesorado oficial del Estado, está claro que no se hace mención alguna acerca de quien lo nombra, es decir, qué autoridad $u$ órgano emana el acto de nombramiento del vocal representante del Profesorado oficial para que se integre en el Tribunal que ha de constituirse.

Se trata, pues, de una laguna que efectivamente debe ser cubierta. ¿Cómo?

Según lo dispuesto por el Reglamento (artículo 235, 2), cuando se trate de plazas de funcionarios técnico-administrativos, formará parte del Tribunal el Jefe de la Abogacía del Estado en la Provincia o Abogado del Estado en quien delegue, y para las oposiciones que se celebren en Madrid, lo designará el Director general de Administración Local. No podemos olvidar que la Abogacía del Estado orgánicamente está encuadrada, como es sabido, en la Dirección General de lo Contencioso del Estado, del Ministerio de Hacienda; pero, pese a ello, la designación la hace el órgano citado, que no tiene relación jerárquica con aquel Cuerpo de funcionarios, y esta cuestión es importante, como después veremos.

Se determina también para el grupo de funcionarios administrativos (artículo 235,4 ) que «en las poblaciones en que existan secciones del Instituto de Estudios de Administración Local, corres ponderá a este Centro designar el representante del Profesorado oficial». Lo que quiere decir que la competencia primaria para hacer el nombramiento del representante del Profesorado oficial del Estado corresponde al Instituto de Estudios de Administración Local, porque ello es consecuencia de que ya la tiene para los secreta- 
rios, interventores y depositarios y oficiales técnico-administrativos, y bien es sabido que a maiore ad minus. Pero carece de ella por una razón territorial, y entonces corresponde a otro órgano. ¿Quién debe ser éste a quien per saltum le viene atribuida? Ante el silencio normativo (7) y por vía de analogía, y también de equidad, además del carácter integrador propio de todo ordenamiento, entendemos que corresponde a la Dirección General de Administración Local y por su delegación al Gobernador civil. Y ello por las siguientes razones:

a) La tutela del Estado sobre las Entidades locales corresponde con carácter general y ordinario al Ministerio de la Gobernación, a través de la Dirección General de Administración Local.

b) La Función Pública Local, cuando no corresponde a la Corporación respectiva, es materia propia de la Dirección General de Administración Local y la sola enumeración de sus órganos concentrados así lo pone de relieve (8).

c) Si la Dirección General de Administración Local designa en Madrid el vocal que ha de representar a la Abogacía del Estado, Cuerpo sobre el que no tiene relación jerárquica alguna, es por esa tutela y competencia, y por idéntica razón debe nombrar, cuando no corresponda al Instituto de Estudios de Administración Local, al representante del Profesorado oficial del Fstado, pues sobre los Cuerpos que lo integran tampoco tiene relación jerárquica alguna.

d) Si la Dirección General de Administración Local aclaró el artículo 26 del Reglamento de Funcionarios por su Resolución de 11 de febrero de 1963, y ello fue corroborado por la sentencia del Tribunal Supremo de 25 de noviembre de 1966 (9), es porque tiene competencia para hacerlo, al recaer sobre la Función Pública Local.

e) Si a tenor de la mencionada Resolución, la representación de la Dirección General de Administración Local en los Tribunales de oposiciones y concursos se entenderá automáticamente otorgada a favor de los asesores-inspectores adscritos al Servicio provincial

(7) La Resolución de la Subsecretaría del Ministerio de Educación y Ciencia de 20 de julio de 1971 (Boletín Oficial del Ministerio de Educación y Ciencia de 16 de agosto) ha atribuido a los Delegados provinciales del Departamento la designación del representante del Profesorado oficial del Estado, y a ella está dedicado el epígrafe $\mathrm{V}$ del presente trabajo.

(8) Vid. el artículo 4.0 del Decreto 986/1974, de 5 de abril (Boletín Oficial del Estado del 16), que reorganiza el Ministerio de la Gobernación, y el artículo $3 .^{\circ}$ de la Orden ministerial de 26 de septiembre de 1974 (Boletín Oficial del Estado del 4 de octubre), que desarrolla el Decreto citado.

(9) Vid. la sentencia en Aranzadi de Jurisprudencia de 1967, referencia 918. 
respectivo de Inspección y Asesoramiento de las Corporaciones Locales que ostenten el título de Letrado y, en otro caso, podrá designarse por el Gobernador civil como tal representante a un funcionario del Cuerpo General Técnico de Administración Civil adscrito al Gobierno Civil; cuando se trate de designar al representante del Profesorado oficial del Estado deberá corresponder al Gobernador civil, pues no sólo es el representante de toda la Administración Central del Estado en la Provincia, sino además también del Ministerio de la Gobernación y de su Dirección General de Administración Local e incluso de los organismos autónomos adscritos a dicho Ministerio; en el caso que nos ocupa del Instituto de Estudios de Administración Local (10). De forma que esa competencia per saltum a que hemos aludido anteriormente no puede ni debe salir del Ministerio de la Gobernación y, dentro de él, de la Dirección General de Administración Local.

$\mathrm{Y}$ esto vale tanto para los funcionarios administrativos como para los técnicos y los especiales.

La praxis ha puesto de relieve que la realidad ha sido otra y que el representante del Profesorado oficial del Estado, aun antes de la Resolución de la Subsecretaría del Ministerio de Educación y Ciencia de 20 de julio de 1971, lo nombraba unas veces el Rector de la Universidad del Distrito correspondiente y otras el Director del Instituto Nacional de Enseñanza Media, según hubiere o no en la Provincia Centro de Enseñanza Superior. La causa de ello estaba, por un lado, en el peso de la tradición, pues recuérdese lo dicho anteriormente sobre funciones de los rectores en los Reglamentos de Secretarios de 1905 y 1916, Estatuto municipal y Real Decreto de 23 de agosto de 1924, y por otro, en que el Rector de la Universidad ha sido, desde que existen Distritos universitarios en España, jefe superior de todos los establecimientos de instrucción pública radicados en él, mientras que los directores de los Institutos sólo tuvieron la representación del Ministerio de Educación y Ciencia a

(10) Como es sabido, el artículo 1.5 del Decreto 986/1974, de 5 de abril (Boletín Oficial del Estado del 16), establece: aAdemás de las facultades que como representante y delegado permanente del Gobierno en las Provincias corresponden a los Gobernadores civiles, los Gobiernos civiles constituirán las Delegaciones provinciales del Ministerio de la Gobernación, a las que estarán subordinadas todas las Jefaturas $u$ oficinas provinciales de las distintas Direcciones Generales del mismo, sin perjuicio de los servicios que puedan establecerse en aquéllas para la asistencia al Gobernador civil en el ejercicio de las facultades anteriormente citadas. El Secretario general del Gobierno Civil podrá asumir, por delegación del Gobernador civil, la Jefatura de todos los servicios civiles de carácter administrativo del Ministerio de la Gobernación en la Provinciad. 
partir de 1955 y hasta 1967, en que fueron creadas las Delegaciones provinciales del Ministerio de Educación y Ciencia (11).

Problema distinto, aunque conexo, es sobre quién debía hacerse la designación, dentro del Profesorado oficial del Estado.

Recordemos nuevamente, según el Reglamento de Funcionarios, que en las oposiciones de funcionarios administrativos se dice sin más: «un representante del Profesorado oficial» (artículo 235, 1); para las oposiciones y concursos de los funcionarios técnicos «un representante del Profesorado oficial del Estado, que habrá de poseer título oficial facultativo o superior en la especialidad" (artículo 245,1$)$ y para las oposiciones y concursos de funcionarios de servicios especiales «un representante del Profesorado oficial del Estado en materias afines a la función». Pero por encima de todos estos preceptos hay que situar la Ley de Régimen local, cuyo artículo 323,1 , recordémoslo, dice:

«El nombramiento de funcionarios, excepto el de Secretario, el de Interventor y el de Depositario, será de la competencia de las respectivas Corporaciones. Se efectuará siempre por oposición o por concurso, juzgados por Tribunales o Comisiones de carácter técnico-administrativo...»,

(11) El artículo 260 de la Ley Moyano, de 9 de septiembre de 1857, decía: «En cada Distrito universitario habrá un Rector, jefe inmediato de la Universidad respectiva, y superior de todos los establecimientos de instrucción pública que haya en él». Además, por Real Decreto de 18 de mayo de 1900, un mes después de haberse creado el Ministerio de Instrucción Pública y Bellas Artes, desglosado del Ministerio de Fomento, se dispuso -artículo 2.-: «El Rector de la Universidad es el representante del Gobierno y el jefe nato de todos los establecimientos oficiales de enseñanza que existan dentro de su Distrito universitarion, y -artículo 6.-: «Para la dirección e inspección de la enseñanza oficial se establece el orden jerárquico, siendo el Rector el jefe de todo el Distrito, y bajo su autoridad los directores de los Institutos de Segunda Enseñanza...n.

Por su parte, la Ley de 14 de abril de 1955, que modificó la Ley Orgánica del Ministerio de Educación Nacional de 10 de abril de 1942, estableció: "La representación del Ministerio estará encomendada a los rectores magníficos en los respectivos Distritos universitarios. Actuarán por delegación de ellos los directores de los centros docentes y de las demás instituciones culturales dependientes del Departamento, dentro de sus respectivas órbitas de competencia. En las localidades donde no haya centros oficiales de Enseñanza Superior, el Director del Instituto Nacional de Enseñanza Media más antiguo representará a la autoridad del Ministerio de Educación Nacionaln.

Las Delegaciones Provinciales del Ministerio de Educación y Ciencia fueron creadas por el artículo 7.4 del Decreto de 27 de noviembre de 1967 (Boletín Oficial del Estado del 28) y reguladas por el Decreto de 25 de septiembre de 1968 (Boletín Oficial del Estado del 18 de octubre) y Orden ministerial de 24 de febrero de 1969 (Boletín Oficial del Estado del 5 de marzo). La Ley General de Educación de 4 de agosto de 1970 les dedica su artículo 141, que ha sido desarrollado por el Decreto de 31 de diciembre de 1970 (Boletín Oficial del Estado del 19 de febrero de 1971).

Un estudio sobre el Distrito universitario nos lo ofrece A. Guarta: El Distrito universitario, Madrid, Escuela Nacional de Administración Pública, 1967. 
y siendo así no debe ser cualquier miembro del Profesorado oficial del Estado el que forme parte de los Tribunales o Comisiones con tal carácter. Quizá haya sido en las oposiciones a plazas de funcionarios técnico-administrativos donde se hayan producido los mayores desaciertos (12), precisamente porque se ha prescindido del verdadero contenido del artículo 323,1 , de la Ley de Régimen local, y también porque si la designación la hacía el Director del Instituto, lógico es que la efectuara entre los docentes del Centro que regía. Mutatis mutandis, también hoy los delegados provinciales del Ministerio de Educación y Ciencia, como veremos más adelante, hacen la designación entre profesores de Centros sobre los que tienen jurisdicción, que no son precisamente los docentes universitarios. Pero fácilmente se comprenderá que siendo fundamentalmente las materias a exigir en las oposiciones señaladas Derecho administrativo, Derecho político, Derecho civil y Hacienda pública, ningún docente de Enseñanza Media resulta ser el más adecuado e idóneo porque tales enseñanzas no se imparten en tales Centros, y consecuentemente el Tribunal queda herido en el carácter técnicoadministrativo que debe tener respecto al vocal representante del Profesorado oficial. Además resulta verdaderamente paradójico que de tales Tribunales forme parte «el Jefe de la Abogacía del Estado en la Provincia o Abogado del Estado en quien delegue», precisamente por su técnica, y lo mismo debemos decir del «asesor-inspector del Servicio de Inspección y Asesoramiento que ostente título de Letrado", y pueda resultar, como hemos visto, que el menos técnico por razón de la materia sea el representante del Profesorado oficial del Estado (13).

(12) Por lo que hemos podido conocer, tenemos que señalar que en oposiciones a plazas de técnico-administrativos, actuaron como vocales representantes del Profesorado oficial del Estado, un catedrático de Instituto de Ciencias Naturales (Ayuntamiento de Lugo), un catedrático de Instituto de Griego (Ayuntamiento de Pontevedra), un catedrático de Instituto de Lengua y Literatura Española (Ayuntamiento de Orense) y más recientemente, y con mayor sorpresa por tratarse de capital de Distrito universitario, vemos en el Boletín Oficial del Estado de 21 de abril de 1975 que el Tribunal juzgador de la oposición convocada para cubrir ocho plazas de.Técnicos de Administración General de la Diputación Provincial de Oviedo está integrado, en representación del Profesorado oficial del Estado, por un catedrático de Instituto de Oviedo, que además es de Latín, y como suplente, por un catedrático del. Instituto de Avilés. A esto debemos añadir el caso expuesto en la nota (1), y podrían sumarse muchos casos más si se expresara la cualidad docente de los representantes del Profesorado oficial del Estado en el Boletín Oficial del Estado al hacerse pública la composición del Tribunal.

(13) A este respecto es preciso señalar las sentencias del Tribunal Supremo de 20 de febrero de 1959 y 26 de enero de 1960 (ambas de la Sala 5.^), recaídas en recursos promovidos precisamente por catedráticos y profesores de Institutos Nacio- 


\section{EL PROFESORADO OFICIAL DEL ESTADO}

La expresión «Profesorado oficial del Estado» o, mejor dicho, «representación del Profesorado oficial del Estado» que, como hemos visto, aparece por primera vez en el Estatuto municipal de 1924 (artículo 247), es un término impreciso, o al menos era, porque ¿qué ha de entenderse por tal? ¿Todos los funcionarios docentes del Estado? (14). ¿Sólo los funcionarios docentes de Cuerpos o plantillas de la Administración del Estado dependientes del Ministerio de Educación y Ciencia? (15). ¿Alcanza también a los funcionarios docentes de organismos autónomos de la Administración del Estado? (16).

Como ya hemos tenido ocasión de manifestar en otra oca-

nales de Enseñanza Media, que anulan parcialmente las Ordenes ministeriales de 27 de marzo de 1958 y 28 de marzo de 1959, respectivamente, «en cuanto pretendian, sin sólida base legal en que apoyarse, imponer con carácter obligatorio a los catedráticos numerarios, profesores especiales y adjuntos numerarios de Institutos, titulares de las cátedras de asignaturas concretas, para la enseñanza de cuyas disciplinas obtuvieron el título base de sus derechos y deberes como funcionarios, con perfecta e individualizada determinación, la extensión de sus actividades docentes a materias científicas distintas a la propia de su Profesorado, extensión inadmisible ya que no existe precepto legal alguno que la autorice, y, por el contrario, se opone a la naturaleza del cargo que desempeñan estos funcionarios, cuya adscripción concreta a la enseñanza de una determinada disciplina se pre. supone en toda la legislación relacionada con los Institutos de Enseñanza Media; es decir, que concreta la oposición a unas pruebas de aptitud teórica especializada en la rama científica que constituye la asignatura, sin relación alguna con otras afines...».

Un comentario a la primera de estas sentencias puede verse en GARCfA DE ENTERRfA, E.: «La interdicción de la arbitrariedad en la potestad reglamentaria», Revista de Administración Pública, número 30, 1959, páginas 132-140.

(14) Si así fuera, habrían de comprenderse todos, tanto los de la Administración Central del Estado como de la Administración Autónoma del Estado, prescindiendo del Departamento ministerial del que dependieran o al que estuvieren adscritos, y tanto si estuvieren integrados en Cuerpos como si fueren personal no escalafonado. La existencia de estos últimos lo pone de relieve la Disposición Transitoria Sexta, 2, de la Ley General de Educación de 4 de agosto de 1970 (Boletín Oficial del Estado del 6).

(15) Admitir esto sería desconocer el artículo $30^{\circ}$ de la Ley de Régimen jurídico de la Administración del Estado, Texto refundido de 26 de julio de 1957, que, conforme a la expresión archiconocida del profesor PÉREZ SERRANo, es una ley básica pero no fundamental.

(16) Hay organismos autónomos que tienen funcionarios o personal exclusivamente docente (Escuela Nacional de Administración Pública, Instituto de Estudios de Administración Local, Escuelas Sociales, Escuela Judicial, Escuela Nacional de Sanidad, etc.). Aunque las Universidades son organismos autónomos y así están clasificadas por el Decreto de 14 de junio de 1962, los funcionarios de los Cuerpos docentes universitarios son de Cuerpos Especiales de la Administración del Estado al servicio de tales organismos autónomos. 
sión (17), entendemos por funcionarios docentes aquellos que tienen como actividad principal y permanente la docencia, con lo que excluimos aquellos funcionarios que, ocasional o temporalmente, prestan funciones docentes, como uno más de los destinos que puedan servir (18). Y siendo así no sólo hay funcionarios docentes del Estado en el Ministerio de Educación y Ciencia, sino también en otros Departamentos munisteriales (19).

Por otra parte, bien es cierto y sabido que la mayoría del Profesorado oficial del Estado está incardinado en el Ministerio de Educación y Ciencia y el número de Cuerpos especiales docentes de él dependientes es actualmente el de 37 (20).

Si utilizamos el lenguaje legislativo, es menester recordar que la Ley de 15 de julio de 1952 (Boletín Oficial del Estado del 17) estableció «la situación de excedencia activa para el Profesorado oficial de Centros docentes dependientes del Ministerio de Educación Nacional», con lo que indirectamente se está reconociendo la existencia de otro Profesorado oficial de Centros docentes dependientes de otros Ministerios, a quienes no alcanzaba la nueva situación administrativa funcionarial establecida (21) (22).

(17) Vid. "La excedencia activa», Boletín de la Universidad Compostelana, número 73 , 1965, páginas 285-309.

(18) Es el caso de los profesores de las Academias y Escuelas Militares de los tres Ejér'citos, Escuela General de Policía, Escuela Oficial de Aduanas, etc.

(19) El Decreto $1.427 / 1975$, de 28 de mayo (Boletín Oficial del Estado del 1 de junio), que asigna coeficientes multiplicadores a los distintos Cuerpos de funcionarios, nos refiere como tales al Cuerpo de Profesores de Enseñanza General Básica de Instituciones Penitenciarias, anteriormente denominado Escala de Personal de Enseñanza de Prisiones y comúnmente llamados Maestros de Prisiones (Ministerio de Justicia), y el Cuerpo de Profesores Numerarios de Escuelas Oficiales de Náutica y Máquinas (Ministerio de Comercio). Por lo demás, ello está recona cido en el artículo 136.1 de la Ley General de Educación.

(20) Vid. el Decreto 1.487/1965, antes citado. A los Cuerpos docentes que menciona habrá que añadir otros, todavía no constituidos, pero creados por la Ley General de Educación -artículo 108.3, d) y e)-, cuyo propósito es reducirlos a 12, mediante la correspondiente integración; y si no fuese posible quedarán en situación «a extinguir» (Disposición transitoria sexta).

(21) Un estudio completo de esta situación administrativa lo ofrecemos en el artículo citado "La excedencia activa». Es de destacar que tal situación se extendió por vía reglamentaria tanto objetiva como subjetivamente y llegó a comprender a funcionarios no docentes, como los inspectores de Enseñanza Primaria, de Enseñanza Media y Médicos-Escolares, por la Orden ministerial de 21 de agosto de 1952 (Boletín Oficial del Estado del 25). Los hechos posteriores han venido a darnos la razón, porque la Ley General de Educación no considera a los inspectores, ni sus Cuerpos, comprendidos en el Profesorado del Estado (vid. artículos 108 y 142).

(22) Tal situación quedó confirmada por el artículo 6.0 de la Ley de Situaciones administrativas de los funcionarios de la Administración Civil del Estado de 15 de julio de 1954, que incorporó a su texto la Ley de 15 de julio de 1952, y fue extinguida por el Texto articulado de la Ley de Funcionarios Civiles de la Administración del Estado de 7 de febrero de 1964 (Boletín Oficial del Estado del 15), 
Pero la Ley General de Educación y Financiamiento de la Reforma Educativa, en el Capítulo II de su Título tercero, bajo el epígrafe "Profesorado estatal», señala en su artículo 107.1:

«El profesorado del Estado se regirá por lo dispuesto en esta Ley y en las normas dictadas en desarrollo de la misma. En lo no previsto, será de aplicación la legislación sobre funcionarios civiles de la Administración del Estado»,

y en el artículo 108:

«1. El profesorado del Estado comprenderá:

a) Profesores de Centros de Educación Preescolar y de Colegios Nacionales de Educación General Básica.

b) Profesores de Institutos Nacionales de Bachillerato.

c) Profesores de Centros de Educación universitaria.

d) Profesores de Centros de Formación Profesional de primero y segundo grados.

2. Los profesores a que se refiere el apartado anterior podrán ser funcionarios de carrera integrados en Cuerpos especiales o personal contratado a todos los niveles, de acuerdo con las normas legales que a tal efecto se dicten.

3. Los Cuerpos especiales a que se refiere el apartado segundo, que dependerán del Ministerio de Educación y Ciencia, serán los siguientes:

a) Cuerpo de Profesores de Educación General Básica, que tendrá también a su cargo la Educación Preescolar.

b) Cuerpo de Catedráticos Numerarios de Bachillerato.

c) Cuerpo de Profesores Agregados de Bachillerato.

d) Cuerpo de Catedráticos Numerarios de Escuelas Universitarias.

e) Cuerpo de Profesores Agregados de Escuelas Universitarias.

f) Cuerpo de Catedráticos Numerarios de Universidad.

g) Cuerpo de Profesores Agregados de Universidad.

h) Cuerpo de Profesores Adjuntos de Universidad.

i) Cuerpo de Profesores de Enseñanzas Especializadas.

j) Cuerpo de Catedráticos Numerarios de Formación Profesional.

k) Cuerpo de Profesores Agregados de Formación Pro fesional».

ya que se integró como un supuesto más de la situación administrativa de supernumerario, aunque reducida al personal docente de grado superior -art. $46.1 d$ )- 
Ante ello, nos surge la pregunta: ¿hemos de entender ahora por el "Profesorado oficial del Estado» a que se refiere la Ley de Régimen local y su Reglamento de Funcionarios, el «Profesorado del Estado" que contempla y regula la Ley General de Educación?

Aunque inicialmente podría darse una respuesta afirmativa, opinamos modestamente que, hoy por hoy, íntegramente no. La Ley General de Educación tiene unos propósitos uniformes que ha de realizar en un plazo de diez años, a partir de 26 de agosto de 1970, fecha en que entró en vigor, pero que todavía no está totalmente implantada y aún queda mucho por desarrollar de los principios y preceptos en ella establecidos.

Pero sí hemos de destacar, en relación con el objeto de este trabajo, un hecho legislativo importante. La Ley de 22 de diciembre de 1970 (Boletín Oficial del Estado del 31), de reestructuración de los Cuerpos penitenciarios, que en su artículo 3.4 dice:

"La actual Escala de Personal de Enseñanza de Prisiones pasará a denominarse Cuerpo de Profesores de Enseñanza General Básica de Instituciones Penitenciarias»,

pero antes ha determinado (artículo $1 .^{\circ}$ ) que estos funcionarios dependerán de la Dirección General de Instituciones Penitenciarias, que, como se sabe, es órgano del Ministerio de Justicia. Con lo cual el mismo legislador viene a reconocer y afirmar que no todo el Profesorado del Estado depende del Ministerio de Educación y Ciencia (23) y que los profesores de Educación General Básica de Instituciones Penitenciarias son Profesorado del Estado. Esto, desde luego, no es sorprendente ni mucho menos, pues la reciprocidad completa entre los maestros de las Escuelas públicas dependientes de la Dirección General de Instrucción Pública (hoy Ministerio de Educación y Ciencia) y los de las Escuelas de los Establecimientos Penales (hoy dependientes de la Dirección General de Instituciones Penitenciarias) está establecida por la Ley de 4 de abril de 1889 (Gaceta del 6), que no ha sido objeto de derogación expresa, por lo que hay que predicar su vigencia a este respecto, conforme al artículo 2.2 del nuevo Título preliminar del Código civil de 31 de mayo de 1974 (24).

(23) Esta es la opinión, que compartimos, del profesor J. L. MenLAN Gil. Vid. el ruego al Gobierno publicado en el Boletín Oficial de las Cortes Españolas número 1387 , de 12 de noviembre de 1974 , página 33804 .

(24) El Decreto $2.763 / 1971$, de 21 de octubre (Boletín Oficial del Estado del 15 de noviembre), dictado en cumplimiento del artículo 145 de la Ley General de Edu- 
Por otro lado, el mismo legislador había manifestado por la Ley 144/1961, de 23 de diciembre (Boletín Oficial del Estado del día 29) (25), artículo 9, lo siguiente:

«1. Los profesores numerarios de las Escuelas Oficiales de Náutica ingresarán por concurso-oposición y constituirán un Cuerpo especial dependiente de la Subsecretaría de la Marina Mercante»(26).

cación, organiza el Consejo Nacional de Educación, y en su artículo 11.2 dispone: aTendrán la consideración de Consejeros designados los nombrados por el Ministro de Educación y Ciencia en la forma siguiente:

f) Un Consejero en representación de cada uno de los Cuerpos de funcionarios docentes, designados entre los veinte funcionarios en servicio activo más antiguos de cada plantilla».

Por Orden ministerial de 28 de enero de 1975 (Boletín Oficial del Estado del 11 de febrero) se designan consejeros nacionales de Educación, en representación de los Cuerpos que se mencionan; aparece la designación del vocal representante del Cuerpo especial de Profesores Numerarios de Náutica, pero no, y nos sorprende, el de "Profesores de Educación General Básica de Instituciones Penitenciarias".

(25) Esta Ley, que reorganiza las enseñanzas de las hasta entonces denominadas Escuelas de Náutica y Máquinas y Escuelas Medias de Pesca y pasan a denominarse, respectivamente, "Escuelas de Náutica» y "Escuelas de Formación Profesional Náutico-Pesquera", establece la distinción fundamental, desde el punto de vista de la organización docente, que aquéllas serán consideradas como Enseñanzas Técnicas de Grado Medio (hoy Escuelas Universitarias, conforme al artículo $75^{\circ}$ y Disposición transitoria segunda de la Ley General de Educación y Decreto 2.498/ 1971, de 17 de septiembre -Boletín Oficial del Estado del 19 de octubre-), y éstas como de Formación Profesional, pero añadirá - artículo 1.3-: «Estas Escuelas, sean oficiales o reconocidas, continuarán dependiendo de la Subsecretaría de la Marina Mercante, y se regirán por las disposiciones que establece esta Ley y por las normas complementarias que se dicten para su desarrollo por el Ministerio de Comercio (Subsecretaría de la Marina Mercante).

A consecuencia de ello, no debe ser aplicada a tales enseñanzas y profesores la Disposición final cuarta de la Ley General de Educación que, como es sabido, deslegaliza, degradándolas a normas de carácter reglamentario, todas las disposiciones anteriores, cualquiera que fuere su rango, que venían regulando "las materias objeto de la misman, dado que la Ley General de Educación no regula las enseñanzas de Náutica, aunque reconoce la existencia de enseñanzas dependientes de otros Ministerios (art. 136.1).

Se hace preciso recordar que las enseñanzas de Náutica eran consideradas como enseñanzas profesionales por el artículo 61 de la Ley de Instrucción pública de 9 de septiembre de 1857 (Ley Moyano), y como tales dependían del Ministerio de Fomento. Creado el Ministerio de Instrucción Pública y Bellas Artes en 1900, el artículo 1.० del Real Decreto de 18 de mayo de 1915 (Gaceta del 30) dispuso que «las Escuelas especiales de Náutica continuarán dependiendo del Ministerio de Instrucción Pública y Bellas Artes». Así estuvieron hasta que el Real Decreto de 1 de febrero de 1924 (Gaceta del 2) dispuso su adscripción a la Dirección General de Navegación y Pesca Marítima del Ministerio de Marina. Creada la Subsecretaría de la Marina Mercante por Ley de 19 de febrero de 1942 (Boletin Oficial del Estado del 7 de mayo), asumió las funciones encomendadas a las Direcciones Generales de Comunicaciones y Pesca Marítima, integrándose en el Ministerio de Industria y Comercio en tiempo de paz, y pasará al Ministerio de Marina en tiempo de guerra. Por Decreto-ley de 19 de julio de 1951 (Boletin Oficial del Estado del 20) se creó el Ministerio de Comercio y en él se comprendieron todos los servicios dependientes de la Subsecretaría de la Marina Mercante.

(26) Los antecedentes de este Cuerpo se encuentran en el Real Decreto de 7 de 
Con lo cual queremos insistir en que, hoy por hoy, no todo el «Profesorado oficial del Estado» es el que depende orgánica y funcionalmente del Ministerio de Educación y Ciencia, aunque cuantitativamente sea el mayor, sino que dicho término comprende, con el espíritu dimanante de la Ley de Funcionarios Civiles de la Administración del Estado, a todos los funcionarios o personal docente, esté o no integrado en Cuerpos especiales, sean de carrera o de empleo, interinos o contratados, que desempeñen puestos o plazas docentes dependientes de la Administración Civil del Estado. Excluimos así, y a los efectos de este trabajo, a los que pudieren ser personal docente de los organismos autónomos, y no sólo porque pertenezcan a personas jurídico-públicas distintas del Estado, sino fundamentalmente porque tales organismos autónomos, a excepción de las Universidades, no imparten enseñanzas que culminen en un título académico, sino que más bien otorgan diplomas o títulos profesionales. Bien es sabido que los llamados títulos académicos son expedidos por el Estado, a través de distintos órganos concentrados y desconcentrados de su Administración Central (27). Todo ello sin olvidar que si bien las Universidades son organismos autónomos de la Administración del Estado, los funcionarios docentes de los Cuerpos de Educación universitaria que en ellas prestan

febrero de 1925 (Gaceta del 19), que aprobó el Estatuto de las Escuelas de Náutica y régimen de su Profesorado, y fue expresamente derogado por el artículo 2.0, a) del Decreto 625/1966, de 10 de febrero (Boletin Oficial del Estado del 22 de marzo), que aprueba el Reglamento de las Escuelas Oficiales de Náutica y de Formación Profesional Náutico-Pesquera, en desarrollo de la Ley 144/1961. Conforme a esta Ley, del personal docente que ella regula sólo constituirán un Cuerpo Especial los profesores numerarios de las Escuelas de Náutica (en el cual las retribuciones económicas serán idénticas a las de catedráticos numerarios de Escuelas Técnicas de Grado Medio) y los demás (maestros de Taller e instructores de Tecnología Naval de Escuelas de Náutica, profesores titulares y maestros de Taller e instructores de Pesca de Escuelas de Formación Profesional Náutico-Pesquera) podrán optar a la condición de funcionario público, con el carácter de permanencia, previo concurso-oposición, cuyas características se determinarán mediante normas especiales.

(27) El artículo 135, f) de la Ley General de Educación dice que "corresponde al Ministerio de Educación y Ciencia, en especial, expedir o autorizar la expedición de los títulos y nombramientos que acrediten conocimientos correspondientes a cualquier nivel o ciclo de enseñanza objeto de esta Ley. Los documentos acreditativos de conocimiento sólo podrán denominarse títulos cuando con tal finalidad hayan sido expedidos o autorizados por el Ministerio de Educación y Ciencia".

No obstante, es sabido que los títulos dimanantes de los estudios de las Escuelas de Náutica (capitán de la Marina Mercante, piloto de la Marina Mercante de primera clase, maquinista naval jefe, oficial de Máquinas de la Marina Mercante de primera clase, piloto de la Marina Mercante de segunda clase, oficial radiotelegrafista de la Marina Mercante de primera y segunda clase) son expedidos por el Ministerio de Comercio; y los títulos de Graduado Social, por el Ministerio de Trabajo. 
REVL-1975, núm. 187. FRUTOS ISABEL, JOSE MARIA DE. EL VOCAL-REPRESENTANTE DEL PR...

EL VOCAL-REPRESENTANTE OFICIAL EN LOS TRIBUNALES DE OPOSICIONES Y CONCURSOS

su actividad lo son de la Administración Central del Estado con destino o al servicio de un organismo autónomo (28).

\section{LA RESOLUCION DE LA SUBSECRETARIA DEL MINISTE- RIO DE EDUCACION Y CIENCIA DE 20 DE JULIO DE 1971}

Estando así las cosas, se emana la Resolución de la Subsecretaría del Ministerio de Educación y Ciencia de 20 de julio de 1971, publicada en el Boletín Oficial del Ministerio de Educación y Ciencia de 16 de agosto, que dispone lo siguiente, y permítasenos la transcripción íntegra:

«Ministerio de Educación y Ciencia. Subsecretarfa. Subdirección General de Coordinación Administrativa. Delegados Provinciales. Facultad.

Ilmos. Sres.: El artículo 235 del Reglamento de Funcionarios de Administración Local dispone, en su número 1., que en la composición de los Tribunales calificadores de opo siciones y concursos de los funcionarios administrativos al servicio de la Administración local figurará un representante del Profesorado oficial, sin determinar a qué autoridad del Departamento corresponde el ejercicio de la facultad para la correspondiente designación.

Reguladas las Delegaciones Provinciales del Departamento por Decreto $3.855 / 1970$. de 31 de diciembre, y en atención a cuanto se dispone en sus artículos primero y tercero,

Esta Subsecretaría ha resuelto:

Primero. Los Delegados provinciales del Departamento designarán a los miembros del Profesorado oficial que deban formar parte de los Tribunales calificadores de oposiciones y concursos de funcionarios de las Corporaciones lo cales, excepto en el supuesto comprendido en el número 4 del artículo 235 del referido Reglamento, que señala la competencia del Instituto de Estudios de Administración Local para efectuar la designación del Profesorado oficial.

Segundo. Por los Delegados provinciales del Departamento se dará traslado de la presente Resolución a las Corpora. ciones locales de la respectiva Provincia».

Muchas consideraciones nos ofrece la transcrita Resolución, y que trataremos de exponer:

(28) Por decirlo de manera más expresiva, son funcionarios «en» y no funcionarios ade». 
1. ${ }^{\mathrm{a}}$ Se trata, como su nombre indica, de una Resolución, con lo que se quiere decir que no es una disposición administrativa de carácter general; por eso no se ha publicado, como sería requisito necesario para su eficacia, en el Boletín Oficial del Estado (artículo 129 de la Ley de Régimen jurídico de la Administración del Estado y 132 de la Ley de Procedimiento administrativo).

2. ${ }^{\text {a }}$ Se ha emanado por la Subsecretaría citada en virtud de que le corresponde «desempeñar la Jefatura superior de todo el personal del Departamento y resolver cuantos asuntos se refieran al mismo" y "disponer cuanto concierne al régimen interno de los servicios generales del Ministerio», conforme al artículo 15.2 y 4 de la Ley de Régimen jurídico de la Administración del Estado.

3. ${ }^{a}$ Se trata de una Circular o Instrucción de servicio, dictada al amparo del artículo 18 de la Ley de Régimen jurídico de la Administración del Estado y artículo $7 .^{\circ}$ de la Ley de Procedimiento administrativo, dirigida a los Delegados provinciales del Ministerio de Educación y Ciencia, en la que el Boletín Oficial del Ministerio de Educación y Ciencia ha sido utilizado como medio de comunicación (29), y la mejor prueba de ello es que se impone a los Delegados provinciales citados la obligación de dar traslado de la misma a las Corporaciones locales de la respectiva Provincia.

Al lado de estas consideraciones positivas caben también las negativas que se indican:

a) En la fecha en que se publica la Resolución -16 de agosto de 1971- ya está vigente la Ley General de Educación desde el 26 de agosto de 1970, que dispone:

"Los Rectores de las Universidades tendrán las funciones y competencias que se les encomienden en esta Ley y en las normas que la desarrollen. En todo caso, ostentarán la autoridad delegada del Ministerio de Educación y Ciencia en el Distrito, así como la representación corporativa de los Centros docentes estatales radicados en el mismon (art. 77, 3);

(29) Es corriente ver en los Boletines Oficiales de los Ministerios, además de leyes y reglamentos ya publicados en el Boletín Oficial del Estado, circulares e instrucciones de servicio, que no necesitarían ser publicadas en los mismos, y prueba de ello es que no todas son publicadas. Pero al recibir los órganos periféricos dichos Boletines, la comunicación a través de ellos constituye, además de un instrumento rápido, un modo de conseguir una celeridad y eficacia con una gran economía de tiempo, medios y servicios.

Lo mismo ocurre, a veces, en el Boletín Oficial del Estado y, entre otros, las instrucciones dirigidas a las Entidades locales para la confección de sus presupuestos, son el más típico ejemplo. 
a... podrá el Gobierno, por Decreto, aprobar el traspaso al Ministerio de Educación y Ciencia de competencias y organismos dependientes de otros Departamentos ministeriales" (art. 138.2);

«El Ministro y demás autoridades superiores del Ministerio de Educación y Ciencia podrán desconcentrar o delegar las competencias que tengan atribuidas en otras autoridades del Departamento, sin más limitaciones que las contenidas en los apartados $a$ ), b), c), d) y e) del artículo 22 de la Ley de Régimen jurídico de la Administración del Estado. La desconcentración deberá ser aprobada por Decreto y la delegación por Orden del Ministro del Departamento" (artículo 139);

«En cada Provincia existirá una Delegación provincial del Ministerio de Educación y Ciencia, que asumirá la responsabilidad de la dirección, coordinación, programación y ejecución de la actividad administrativa del Departamento en aquélla, a excepción de los Centros de Educación universitaria y sin perjuicio de lo dispuesto en el apartado 3 del artículo 77" (art. 141.1);

y está vigente también el Decreto $3.855 / 1970$, de 31 de diciembre (Boletín Oficial del Estado del 19 de febrero), en cuyo artículo $1 .^{\circ}$ se reproduce en su apartado 1 el artículo 141.1 de la Ley General de Educación, y en el apartado 2 el artículo 139, pero en el apartado 3 se dirá:

«El Ministerio de Educación y Ciencia adoptará o propondrá al Gobierno, según proceda, las medidas necesarias para establecer una adecuada desconcentración o delegación de las facultades de resolución o propuesta hasta ahora atribuidas a las autoridades y servicios centrales, y que pueden realizarse en las Delegaciones provinciales con mayor celeridad, economía y comodidad de los particulares".

Ante todo esto debemos manifestar:

- El Ministerio de Educación y Ciencia tiene dos tipos de órganos como autoridades periféricas y con competencias específicas cada uno de ellos, tanto funcionales como territoriales: los Rectores de las Universidades y los Delegados provinciales del Departamento, y ambos son nombrados por Decreto, pero sólo atribuye a aquéllos la representación de los Centros docentes estatales radicados en los Distritos universitarios que rijan.

- La Resolución de la Subsecretaría de Educación y Ciencia no 
es el resultado ni de una desconcentración ni de una delegación, y aunque así se considerase sería ineficaz, porque aquélla requeriría un Decreto y ésta una Orden ministerial, circunstancias que no se dan en el presente caso. Además no puede ser objeto de desconcentración o delegación una competencia - la designación del representante del Profesorado oficial del Estado- que específicamente no se tenía ni se ejercía.

- La Resolución de la Subsecretaría de Educación y Ciencia contiene una atribución de funciones (30), cosa distinta a la desconcentración y a la delegación.

- Si la atribución de funciones se hace a los Delegados provinciales del Departamento, al no tener éstos competencia sobre los Centros de Educación Universitaria y consecuentemente sobre su Profesorado, porque está atribuida a los Rectores, conforme al artículo 77.3 y en relación con el artículo 141, ambos de la Ley General de Educación, resulta que los profesores universitarios, en sus diferentes Cuerpos, que son Profesorado oficial del Estado o Profesorado del Estado, como hemos visto, no podrían ser nombrados vocales de los Tribunales juzgadores de oposiciones y concursos de la Administración local, y sólo quedaría reducido a los demás funcionarios docentes dependientes del Ministerio de Educación y Ciencia radicados en la Provincia. Con lo cual y por la misma razón quedarían también excluidos los demás funcionarios docentes del Profesorado del Estado no dependientes del Ministerio de Educación y Ciencia.

- No existen en todas las Provincias los mismos Centros docentes (vg. Conservatorios de Música, Escuelas de Artes Aplicadas y Oficios Artísticos, Escuelas Periciales de Comercio, etc.), de tal forma que si fuere precisa la participación del Profesorado de estos Centros, la designación de los mismos tampoco podría hacerse, porque los Delegados provinciales carecerían de competencia territorial, circunstancia que no desaparecería aunque mediara propuesta del Delegado provincial competente territorialmente.

- Con lo dicho podrá conseguirse, sí, pero no siempre, economía, celeridad y eficacia, pero queda preterida la idoneidad, que debe ser el principio informador y previo a todos los demás.

- Por otra parte, y esto es fundamental, si tenemos en cuenta

(30) Vid. Giannini: aGli elementi degli ordinamenti giuridici», en Rivista Trimestrale di Diritto Pubblico, 1958, 2, y en nuestra Patria J. A. Garcfa-Trevijano Fos: Tratado de Derecho Administrativo, vol. I del tomo II, 2: ed., págs. 393-395. 
el contenido de la Resolución cuestionada, apreciamos que se trata de regular una materia que, como es la Función Pública Local, ha estado tradicionalmente atribuida al Ministerio de la Gobernación y a las Corporaciones locales, y a mayor abundamiento estaba prácticamente muy reciente la Ley 79/1968, de 5 de diciembre, de Bases de funcionarios de la Administración local, cuya Base II es singularmente clarísima y la Subsecretaría de Educación y Ciencia parece preterir.

- Finalmente, la reiterada Resolución es incompleta, porque sólo se refiere a la designación del representante del Profesorado oficial del Estado en oposiciones y concursos para el grupo de funcionarios administrativos, a quienes está dedicado el artículo 235 del Reglamento de Funcionarios locales, y no dice nada para los funcionarios técnicos ni los de servicios especiales.

b) En la fecha en que se dicta la Resolución que nos ocupa también está vigente, aprobado por Decreto 1.411/68, de 27 de junio (Boletín Oficial del Estado del 29), el Reglamento general para ingreso en la Administración pública, «en cualquiera de sus grados y esferas", y aplicable natural y explícitamente a la Administración local. Pues bien, conforme a él -artículo $10^{\circ}$ -

«El procedimiento de selección para el ingreso en la Admi. nistración pública se regirá por las bases de la convocatoria respectiva, que se ajustarán, salvo que por ley se hayan establecido normas especiales, a lo determinado en este Reglamento, y en lo no previsto en el mismo, a las disposiciones específicas aplicables en cada cason.

Y el artículo 6.1 dirá:

«Después de publicada la lista de aspirantes admitidos y excluidos se nombrará el Tribunal por la autoridad competente...» (31).

(31) Este precepto es reproducción literal del consignado en el artículo 8.1 del Reglamento de Oposiciones y Concursos aprobado por Decreto de 10 de mayo de 1957 (Boletin Oficial del Estado del 13), que ha quedado expresamente derogado por aquél. Esta derogación expresa ha de plantear problemas porque el Reglamento de 1957 es de oposiciones y concursos y el de 1968 es sólo de ingreso en la Administración pública. De tal forma que cuando el concurso no es forma de ingreso, sino de provisión de plaza o plazas determinadas entre quienes ya son funcionarios, de no haber norma específica habrá que acudir al Reglamento de 1957, porque la derogación sólo debe alcanzar al procedimiento de ingreso, pero nada más, pues éste no es incompatible con aquél, conforme determina el artículo 2.2 del Título preliminar del Código civil vigente, Texto articulado de 31 de mayo de 1974. 
Es decir, el Tribunal, órgano transitorio de naturaleza colegial, ha de ser nombrado por la autoridad competente, normalmente la convocante, pero en un solo acto, pero ello naturalmente excluye un nombramiento parcelario y por órganos distintos, bien sea su actuación coetánea o sucesiva (32).

c) Allí donde se hace una atribución de funciones forzosamente existe una norma, y máxime cuando de ella deriva una competencia externa. Y este necesario carácter normativo tiene la Resolución de la Subsecretaría de Educación y Ciencia que nos ocupa, la cual por su contenido es un auténtico reglamento, una disposición administrativa de carácter general. A este propósito bien oportuno es recordar lo que el Tribunal Supremo ha establecido en sus Sentencias de 28 de noviembre y 1 de diciembre de 1961:

«no puede decirse norma aclaratoria de una disposición la que viene a desenvolverla con disposiciones nuevas, pues la calidad de una norma no depende del nombre que se la dé, sino de lo que dispone; no es cuestión de nomenclatura, sino de contenido, y si en realidad una norma es reglamentaria, a esta cualidad se debe estar...».

Y si es una norma hay que examinar la competencia para emanarla. De todos es conocido que conforme a nuestro Derecho positivo los Subsecretarios no tienen potestad reglamentaria, que corresponde a los Ministros, y éstos no pueden delegarla en los Subsecretarios (arts. 14, 18 y 22.3-d de la Ley de Régimen jurídico de la Administración del Estado), necesitando como requisito de eficacia su publicación en el Boletín Oficial del Estado (arts. 132 de la Ley de Procedimiento administrativo y 29 de la Ley de Régimen jurídico de la Administración del Estado), y la doctrina es de la misma opinión (33).

Pero hay más; la Resolución cuestionada no ha tenido tampoco en cuenta que las Corporaciones locales pueden tener sus propios Reglamentos de funcionarios, conforme a la Disposición final cuarta del Decreto de 30 de mayo de 1952 (Boletín Oficial del Estado del

(32) Sobre este punto, volveremos más adelante, epígrafe VI: «La competencia normativa en la Función Pública Localn.

(33) Por todos, J. M. Boquera Oliver: «Los órganos estatales titulares de poder reglamentarion, Revista de Administración Pública, número 47, página 92, quien concluye: aEn resumen, el poder reglamentario, salvo casos de concesión singular y expresa por una ley, no rebasa nunca, en nuestra Administración Central, la línea de los jefes de los Departamentos ministeriales. Ni siquiera por delegación podrá una autoridad inferior dictar reglamentos». 
28 de junio), que aprueba el Reglamènto general de Funcionarios de la Administración local, y es perfectamente posible y lícito que en ellos se pudiera regular cuál fuere la forma o procedimiento de designación del vocal representantes del Profesorado oficial del Estado. Naturalmente que si así fuera, tal Resolución de la Subsecretaría sería inoperante y nula, porque supondría una vulneración del principio de inderogabilidad singular de Reglamentos, establecido, como es sabido, por el artículo 30 de la Ley de Régimen jurídico de la Administración del Estado.

Por último, y aun en el supuesto de que tal Resolución tuviere el ropaje externo de una Orden ministerial del mismo Departamento, y fuere un auténtico Reglamento, también tendríamos que predicar su nulidad, no sólo por lo que queda dicho, sino porque excluiría al resto del Profesorado oficial del Estado no dependiente de dicho Ministerio, y además porque, a tenor del artículo 25.2 de la citada Ley de.Régimen jurídico, debería ser emanada por el Ministro de la Gobernación, a propuesta de los Ministros de Educación y Ciencia, Justicia y Comercio, o por el Ministro de la Presidencia, a propuesta de todos los Ministros ya citados.

Por todo ello predicamos la nulidad de pleno derecho de la Resolución de la Subsecretaría de 20 de julio de 1971, pues además de todos los vicios expresados, entendemos que la representación del Profesorado oficial del Estado no es propiamente de Cuerpos de funcionarios, sino de Claustros de los diferentes grados docentes y ésta corresponde ejercerla al Rectorado de la Universidad correspondiente, por determinación expresa de la Ley General de Educación, que recoge un criterio que, como se ha visto, tiene ya un peso histórico desde la Ley Moyano.

\section{LA COMPETENCIA NORMATIVA EN LA FUNCION PUBLICA LOCAL}

La competencia en la Función Pública Local tradicionalmente, y desde que existe el Ministerio de la Gobernación, siempre ha estado atribuida, desde el punto de vista de la intervención del Estado y dejando a salvo la potestad legislativa, a dicho Departamento ministerial, en el cual ha sido órgano casi permanente, como es sabido, la Dirección General de Administración, denominada ulteriormente, como lo es hoy, Dirección General de Administración Local. 
Y además también a las propias Corporaciones que desde la Ley de 1870 han podido elaborar sus respectivos Reglamentos de funcionarios, subordinados, como es natural, a las Leyes y Reglamentos generales.

Por no referirnos más que a las normas inmediatamente anteriores a la Resolución de la Subsecretaría de Educación y Ciencia de 20 de julio de 1971, que debía haber tenido presente su inspirador, hemos de citar, por lo claro y tajante, la Ley 79/1968, de 5 de diciembre (Boletín Oficial del Estado del 7), de Bases de Funcionarios de Administración Local, que no es fundamentalmente innovadora, sino continuadora, de la tradición existente (34). Pues bien, su Base II prescribe:

\section{«Organos de la función pública local:}

1. Corresponde a las Corporaciones locales la competencia en materia de personal al servicio de las mismas, sin perjuicio de lo dispuesto en esta Ley respecto de las facultades que se atribuyen al Ministerio de la Gobernación y a la Dirección General de Administración Local.

2. Corresponde al Ministro de la Gobernación la elaboración y, en su caso, la saprobación de las disposiciones generales y reglamentarias referentes a la función pública de la Administración local.

3. La Dirección General de Administración Local estará facultada para:

c) En cuanto a los demás grupos de funcionarios, señalar, previo informe del Instituto de Estudios de Administración Local, las bases y programas mínimos de ingreso" (35).

(34) Tradición que se reitera en el Proyecto de Ley de Bases del Estatuto del Régimen local remitido por el Gobierno a las Cortes en mayo de 1974, y actualmente pendiente de las mismas, cuya Base 39, titulada aLa función pública local», afirma: «Se regirá por las Bases aprobadas por la Ley $79 / 1968$, de 5 de diciembre...», y la 41, titulada «Organos de la Administración del Estado competentes en materia de Administración local», determina: «1. Las funciones que la Administración del Estado desempeña respecto de la Administración local corresponderán al Ministerio de la Gobernación, sin perjuicio de las relativas a presupuestos, ordenanzas y exacciones que corresponderán al Ministerio de Hacienda, así como de las atribuciones que en materia específica están asignadas por ley a otros Departamentos ministeriales».

(35) La suspensión del mandato contenido en la Disposición final primera de la Ley 89/1968, para que el Gobierno promulgara el Texto articulado, hecha por el artículo 1.2 del Decreto-ley 23/1969, de 16 de diciembre (Boletín Oficial del Estado del 17), no altera la competencia atribuida por aquélla. Dicha suspensión, como es sabido, ha sido dejada sin efecto por el artículo $10^{\circ}$ del Decreto-ley $7 / 1973$, de 27 de julio (Boletín Oficial del Estado del 3 de agosto), a cuyo tenor, párrafo segundo, el Gobierno ha emanado los Decretos 687, 688 y 689 de 1975, todos ellos de 21 de 
La autonomía provincial y municipal debe tener una manifestación más en el nombramiento de los Tribunales juzgadores de oposiciones y concursos para la selección de sus respectivos funcionarios. No puede negarse a los Entes locales lo que pueden hacer los organismos autónomos de la Administración del Estado, cuando unos y otros responden a un principio de descentralización. No puede negarse a los Entes locales que lo que puedan hacer en unos casos, nombrar el Tribunal juzgador de concursos para la provisión de plazas de funcionarios subalternos, no lo puedan hacer para los demás, cuando la razón de ser, la razón de derecho, es y debe ser la misma. ¿Se ha olvidado ya el principio a minore ad maius? No se puede negar a los Entes locales el principio de unidad de expediente, y puedan realizar el acto inicial, convocar una oposición o concurso, y el final, nombrar a los funcionarios seleccionados, y no puedan efectuar el acto intermedio, nombrar el Tribunal juzgador. Se ha dicho que "la autonomía local es mucho más jurídica que política» (36), pero en la cuestión que estudiamos, y no hay duda que es estrictamente jurídica, parece quebrarse y justo es que se restablezca, pues los principios informadores también lo deben ser de sus consecuencias.

\section{LA EQUIPARACION DE LOS FUNCIONARIOS LOCALES A LOS DE LA ADMINISTRACION DEL ESTADO}

Como es sabido, la Disposición final segunda de la Ley 48/1966, de 23 de julio (Boletín Oficial del Estado del 25), establecía que el Gobierno remitiría a las Cortes un Proyecto de Ley acomodando el régimen y retribución de todos los funcionarios al servicio de las Corporaciones locales, a las directrices y normas aplicables a los funcionarios civiles del Estado, y fruto de ello fue la Ley 79/ 1968, de 5 de diciembre (Boletín Oficial del Estado del 7), de Bases de los Funcionarios de Administración Local, y según señala su preámbulo «en el presente texto se reproducen sustancialmente los principios de la Ley de Bases de 20 de julio de 1963 de funcionarios de la Administración Civil del Estado.

marzo (Boletin Oficial del Estado del 5 de abril), regulando provisionalmente los Cuerpos Nacionales de Administración Local, los Funcionarios de Administración Especial y de Administración General de las Corporaciones locales, respectivamente.

(36) Vid. A. Carro Martfnez: "Las competencias locales», en Problemas politicos de la Vida local. Curso XIV. El crecimiento urbano, Madrid, Delegación Nacional de Provincias del Movimiento, 1974, páginas 113-120. 
Pero esta equiparación ya había sido iniciada en 1957 cuando se emanó el Reglamento general de Oposiciones y Concursos de 10 de mayo (Boletín Oficial del Estado del 13), aplicable tanto a la Administración central del Estado y sus Organismos autónomos como a la Administración local.

Conforme al mismo (art. 8):

«1. Después de publicada la lista de aspirantes admitidos y excluidos, se nombrará el Tribunal por la autoridad competente, haciéndose pública su composición en los periódicos oficiales...

2. Cuando el nombramiento del Tribunal o de alguno de sus miembros sea contrario a las disposiciones vigentes...»,

lo que nos quiere decir que el Tribunal debe ser nombrado por un órgano, unipersonal o colegiado, pero uno solo, con lo que queda fuera la posibilidad de que el Tribunal resulte formado por tantos actos de nombramiento como miembros tenga el mismo.

Ese precepto 8.1 se reproduce en el artículo 6.1 de la nueva reglamentación general para ingreso en la Administración pública, en cualquiera de sus grados y esferas, aprobado por Decreto de 27 de junio de 1968, que ha derogado expresamente al Reglamento anterior (37).

Como es sabido, en la Administración central del Estado, tanto si se trata de funcionarios de Cuerpos generales como especiales, la convocatoria de la oposición o concurso, el nombramiento del Tribunal y el nombramiento de los funcionarios seleccionados se hace por Orden ministerial, bien sea dictada directamente o en virtud de delegación.

Los mismos actos en los Organismos autónomos de la Administración del Estado son realizados por el Director del Organismo respectivo, a tenor de lo establecido por el Estatuto de personal al servicio de los Organismos autónomos, aprobado por Decreto de 23 de julio de 1971 (Boletín Oficial del Estado del 4 de septiembre) (38).

Esto no se produce, pese a la equiparación del régimen, con los funcionarios de la Administración local no pertenecientes a Cuer-

(37) Vid. anteriormente nota (31).

(38) Debe señalarse que previamente al nombramiento de los funcionarios de los organismos autónomos debe existir la Orden ministerial de aprobación, conforme al artículo $6.5, c)$ del Estatuto; una manifestación más de la tutela administrativa a posteriori del Estado sobre el Ente. 
pos nacionales, pues, como hemos visto, la convocatoria de oposiciones o concursos corresponde hacerla al órgano municipal o provincial que ulteriormente haga el nombramiento de los funcionarios, pero no ocurre lo mismo, a excepción del personal subalterno, cun el nombramiento del Tribunal, que, recordemos, no se nombra, sino que resulta nombrado, se hace público y ulteriormente se constituye.

Se hace, pues, preciso, como consecuencia de la equiparación del régimen que inspira el sistema selectivo de los funcionarios de la Administración local, y además por imperativo del Reglamento general para ingreso en la Administración pública, que el Alcalde, Comisión Municipal Permanente, Ayuntamiento Pleno o Diputación provincial, según su específica y respectiva competencia, designen el Tribunal juzgador de oposiciones y concursos. Ello no constituiría ninguna novedad, pues conforme al Reglamento de 23 de agosto de 1924 (arts. 94 y 97), «el Ayuntamiento nombrará el Tribunal en las oposiciones o concursos", y al artículo 15 del Reglamento de 14 de mayo de 1928: "En los Tribunales que designen las Corporaciones...", así ha sido.

La cuestión no es baladí, sino importante, y puede tener múltiples consecuencias. Si el Tribunal no se nombra, sino que resulta nombrado, ¿ante qué órgano debe formularse la posible impugnación del mismo? No puede haber una impugnación del acto de nombramiento del Tribunal, sino de los actos de nombramiento de Presidente, de cada uno de los vocales o de Secretario del Tribunal y ante el órgano o autoridad que hizo el nombramiento respectivo o su superior jerárquico. Lo mismo cabe decir respecto de las abstenciones, recusaciones, renuncias, sustituciones y casos semejantes.

Si pensamos en el representante del Profesorado oficial del Estado designado por el Delegado provincial del Ministerio de Educación y Ciencia, la impugnación procedente sería un recurso de alzada ante el Director general de Personal o ante el Director general de Universidades e Investigación, según no fuere o fuere Profesor de Cuerpos docentes universitarios.

Al no ser el nombramiento del vocal representante del Profesorado acto municipal o provincial no puede haber sobre el mismo, conforme al Ordenamiento jurídico local, advertencia de ilegalidad por el Secretario, ni suspensión del acuerdo por el Presidente de la Corporación, ni tampoco por el Gobernador civil, pese a tratarse de 
una materia que inequívocamente es de Administración local (39). Todo ello carece de lógica y congruencia, requisitos necesarios de todo Ordenamiento jurídico, y creemos que el Ordenamiento jurídico local los tiene, y es contrario a ella que el nombramiento de un Tribunal de oposiciones o concursos no lo pueda hacer una Corporación local, a través de sus órganos competentes. Además, así debería ser si se tuviere en cuenta el principio unitivo que se deriva del artículo 39 de la Ley de Procedimiento administrativo, supletorio de las normas procedimentales locales.

Por último, es también esencial que todo acto administrativo sea garantizador e inequívoco. Si el Presidente de la Corporación hace público el Tribunal juzgador de oposiciones y concursos para la selección de funcionarios de la Administración local, el opositor o concursante admitido y cualquier persona legitimada para impugnarlo se creerá que se trata de un acto municipal o provincial y como tal pretenderá la impugnación en el plazo de un mes mediante el recurso de reposición pertinente, pero se encontrará que si impugna el nombramiento del vocal representante del Profesorado oficial del Estado el recurso procedente será el de alzada en el plazo de quince días. Pero ello requerirá, porque en los actos de publicación del Tribunal no se dice quién hizo el nombramiento, que la Entidad municipal o provincial comunique al posible recurrente qué procedimiento tiene que seguir y ante qué órgano, porque ésa será la auténtica notificación a los efectos impugnatorios.

Como vemos, un complejo sistema que está bien lejos de la sencillez que pretenden las normas procedimentales y que así resultaría si efectivamente, y como debiera ser, los órganos municipales y provinciales pertinentes hiciesen el nombramiento de los Tribunales, aunque fuere a propuesta, por lo que toca al representante del Profesorado oficial del Estado, del órgano pertinente periférico del Ministerio de Educación y Ciencia. A este propósito tajante y claro responde el artículo 214 del Reglamento de Funcionarios de la Administración Local, que determina expresamente, como ya se ha

(39) Pensamos que el Gobernador civil podría suspender el nombramiento hecho por el Delegado provincial del Ministerio de Educación y Ciencia al amparo del artículo 13, párrafo cuarto, del Estatuto de Gobernadores Civiles de 10 de octubre de 1958 (Boletín Oficial del Estado del 9 de diciembre), pero ello es problemático, pues se hace difícil pensar que sobre la cuestión haya directrices del citado Ministerio y que los Gobernadores civiles hayan dispuesto con carácter general que se les notifique por los Delegados provinciales de Educación sus resoluciones sobre esta materia, requisitos necesarios, conforme a los párrafos primero y segundo del citado artículo, para que así sea posible. 
visto, que uno de los vocales del Tribunal juzgador de las oposiciones a ingreso en el Cuerpo Técnico de Directores de Bandas de Música Civiles sea «un Profesor de Composición o de Armonía del Real Conservatorio de Música y Declamación de Madrid, propuesto por el Director del Centro».

Pues bien, ante el silencio de dicho Reglamento respecto de los demás casos en que ha de intervenir el representante del Profesorado oficial del Estado y para mantener un criterio uniforme, que es el propósito que lo inspira, es y resulta ortodoxo que quien "ostenta la representación corporativa de los Centros docentes estatales radicados en el Distrito Universitario", es decir, el Rector de la Universidad, conforme al artículo 77.3 de la Ley General de Educación, sea quien efectúe la propuesta a la Corporación requirente.

\section{EL PRINCIPIO DE ESPECIALIDAD DE LOS TRIBUNALES}

Creo no puede ofrecer duda que el principio inspirador de todo sistema de selección de los funcionarios públicos, en todas las esferas y grados, a través de oposiciones, concursos y concursos- oposiciones, es la determinación de quienes sean los más aptos, y ello requiere como premisa que quienes efectúan la selección sean a su vez los más adecuados por razón de su actividad para realizarla; de ahí el carácter vinculante que tiene su propuesta para los órganos competentes llamados a efectuar los pertinentes nombramientos.

Este que podemos denominar principio de especialidad de los Tribunales es lo que para la Administración local está inspirando el artículo 323 de la Ley de Régimen local cuando dice, recordemos, «... por oposición o por concurso, juzgados por Tribunales o Comisiones de carácter técnico-administrativo", combinado con el principio de jefatura o dirección que supone la afirmación del mismo artículo, y seguidamente, «que presidirá un representante de la Corporación interesada".

Este principio de especialidad es el que, referido a los vocales de los Tribunales de oposiciones y concursos, regula después los diferentes preceptos ya citados del Reglamento de Funcionarios de Administración Local y según sea la clase de funcionarios a seleccionar. Pero lo que repugna a ese principio de especialidad, respecto al vocal representante del Profesorado oficial del Estado, es que, a través de su práctica, se destaque el carácter personal del funcio- 
nario - un profesor oficial del Estado- y prevalezca sobre la función docente específica que tiene a su cargo - profesor de Derecho administrativo, Derecho político, Derecho tributario, Contabilidad general, Estadística y Métodos estadísticos, Archivística, Paleografía, etc.-, cuando el espíritu es bien distinto, y está muy claro para los funcionarios técnicos y especiales, como ya hemos visto, y así debe primar la especialidad de la función docente dentro del carácter funcionarial del profesor. La interpretación de la norma así hecha resultaría lógica, congruente, equitativa y garantizadora. Además, la pluralidad de Cuerpos docentes en los diversos grados de la enseñanza hace perfectamente posible que la docencia de materias propias de la oposición o el poseer títulos iguales o superiores a los exigidos en el concurso, sean las causas determinantes de la designación, pues entendemos que el representante del Profesorado oficial del Estado lo es de la docencia que imparte y no de la mera pertenencia a un Cuerpo de Funcionarios (40) (41).

Conforme, pues, con el criterio de que el Tribunal debe ser nombrado por el órgano municipal o provincial que hizo previamente la convocatoria y ulteriormente hará el nombramiento, se hace preciso también determinar el procedimiento de designación del que sea representante del Profesorado oficial del Estado, y para ello no se puede prescindir, sino tener muy en cuenta, cuáles son los Cuerpos docentes del Profesorado del Estado, la organización desconcentrada del Ministerio de Educación y Ciencia y los Centros docentes estatales existentes, y sea quien ostente la representación corporativa de éstos, el Rector de la Universidad, quien efectúe la propuesta pertinente, pues es innegable que en el ejercicio de dicha representación bien puede determinar cuál puede ser el profesor o profesores más idóneos para formar parte del Tribunal juzgador de la oposición o concurso a la vista de las bases y programa de la misma, y ejercer dentro de él su función profesoral como una manifestación más de su contenido. Naturalmente ello no obsta para que tal facultad rectoral pueda ser objeto de delegación, cuan-

(40) Con estos criterios los casos expuestos en la nota (12) no pueden producirse.

(41) Es curioso observar cómo en alguna ocasión se ha determinado este principio de especialidad, y a tal efecto conviene recordar la Real Orden Circular de 11 de marzo de 1924 (Gaceta del 18) del Ministerio de Instrucción Pública y Bellas Artes, en virtud de la cual se interesa ade los señores Rectores de las Universidades del Reino la organización de conferencias de divulgación del nuevo Estatuto Municipal, a cargo de los señores catedráticos de Derecho político, Derecho administrativo, Hacienda pública y Economía política, quienes prestarán de tal suerte un importante servicio relacionado con el interés público». 
do el título exigible o las materias propias de la oposición o concurso no sean específicos de los Centros de educación universitaria, en los Directores de los Centros docentes pertinentes, prevaleciendo en todo caso la especialidad de la función docente.

A tal efecto, sugerimos:

a) Que corresponda al Rector de la Universidad del Distrito pertinente la propuesta de nombramiento del vocal-representante del Profesorado oficial del Estado, entre funcionarios docentes de Facultades, Escuelas Técnicas Superiores y Escuelas Universitarias, en las oposiciones y concursos de los siguientes grupos de funcionarios de Administración local:

- Técnicos de Administración General.

- Administrativos de Administración General.

- Técnicos Superiores de Administración Especial.

- Técnicos Medios de Administración Especial.

- Escala de Mando de la Policía Municipal.

- Empleos de Suboficial y Sargento de la Policía Municipal.

b) Que corresponda al Rector de la Universidad del Distrito pertinente, con facultad de delegación en los Directores de los Centros estatales más adecuados, entre funcionarios docentes de Institutos Nacionales de Bachillerato, Centros de Formación Profesional, Escuelas de Artes Aplicadas y Oficios Artísticos, Conservatorios de Música y Declamación y Colegios Nacionales de Educación General Básica, según la titulación exigible o materias propias de la oposición o concurso, para los siguientes grupos de funcionarios:

- Auxiliares de Administración General.

- Técnicos auxiliares de Administración especial.

- Empleos de Cabo y Guardia de la Policía Municipal.

- Auxiliares de la Policía Municipal.

- Plazas del Servicio de Extinción de Incendios.

- Otro personal de Servicios Especiales.

c) En todo caso, la propuesta se hará en favor del profesor o profesores más idóneos, según su titulación académica y especialidad docente, para la plaza o plazas objeto de provisión mediante oposición, concurso-oposición o concurso.

d) La propuesta, por razones de economía y celeridad, deberá realizarse en favor de profesor o profesores que tengan su destino o puesto docente en el Municipio donde tenga su sede la Corpora- 
ción local o, en su defecto, dentro de la misma Provincia o Distrito universitario.

Para el caso de que no hubiere en el Distrito universitario Centro estatal con profesorado idóneo, a tenor de la especialidad de la plaza, a juicio del Rector de la Universidad, o el profesorado fuere dependiente de Departamento ministerial distinto del de Educación y Ciencia, el Rector de la Universidad del Distrito universitario requerido comunicará a la Corporación local requirente a qué órgano universitario (normalmente Rector de Universidad politécnica) o docente ha de dirigirse para que le sea formulada la propuesta.

Publicados y vigentes los Decretos 688/1975 y 689/1975, ambos de 21 de marzo (Boletin Oficial del Estado del 5 de abril) y establecido en la Disposición final primera del primero y en el artículo 12 del segundo, respectivamente, que "por el Ministerio de la Gobernación se dictarán las normas precisas para la ejecución y desarrollo de este Decreto", parece llegado el momento de que este Departamento ministerial defienda y ejercite su propia competencia en el ámbito de la Función Pública Local, regule que corresponde a las Corporaciones locales, según la competencia atribuida a sus órganos, el nombramiento de los Tribunales juzgadores de oposiciones y concursos, y evite las consecuencias que han quedado apuntadas.

No obstante, si persisten las cosas como están y ante la nulidad de pleno derecho de la Resolución de la Subsecretaría del Ministerio de Educación y Ciencia de 20 de julio de 1971, es incuestionable que corresponde a los Rectores de las Universidades el nombramiento del vocal-representante del Profesorado oficial del Estado en los Tribunales juzgadores de oposiciones y concursos para la provisión de plazas de funcionarios de Administración local no pertenecientes a Cuerpos nacionales, cuando no exista Sección del Instituto de Estudios de Administración Local.

\section{CONCLUSIONES}

Como fruto de nuestro trabajo ofrecemos las siguientes conclusiones: 
Primera. Los Tribunales juzgadores de oposiciones y concursos para la provisión de plazas de funcionarios de la Administración local, no pertenecientes a Cuerpos nacionales, deben ser nombrados en unidad de acto por los órganos de las Corporaciones locales, según su respectiva competencia, sobre todo a partir de la entrada en vigor del Reglamento general de ingreso en la Administración pública, y no limitarse, como ocurre actualmente, a hacerlos públicos.

Es singularmente anómalo e incongruente, como la praxis pone de relieve, que las Corporaciones locales puedan convocar una oposición o concurso, acto inicial, y nombrar ulteriormente los funcionarios propuestos por el Tribunal, acto final, y no puedan realizar el nombramiento del Tribunal, acto intermedio.

La unidad de procedimiento, la celeridad y eficacia que debe presidirlo, el sistema de garantías, el precedente normativo y la autonomía municipal y provincial, así lo exigen.

Segunda. La Resolución de la Subsecretaría del Ministerio de Educación y Ciencia de 20 de julio de 1971 es nula de pleno derecho porque, entre otros vicios que contiene, está dictada con manifiesta incompetencia, $\mathbf{y}$ al atribuir a los Delegados provinciales del Ministerio de Educación y Ciencia la facultad de designar los representantes del Profesorado oficial del Estado en los Tribunales juzgadores de oposiciones y concursos de la Administración local se la ha restado a los Rectores de Universidad, que históricamente la han tenido y la tienen expresamente por disposición concreta del artículo 77.3 de la Ley General de Educación.

Tercera. Los referidos Tribunales responden y deben responder a un principio de especialidad, y como tal el representante del Profesorado oficial del Estado lo es de la función docente específica que tiene atribuida y no sólo un mero perteneciente a un Cuerpo de funcionarios.

Cuarta. El vocal-representante del Profesorado oficial del Estado debe ser designado normalmente a propuesta del Rector de la Universidad del Distrito, directamente y con posibilidad de delegación en otros órganos docentes, procurando que la especialidad de la plaza o título exigible se corresponda con la especialidad de la función docente del profesor. 
Quinta. Cuando la especialidad de la plaza o título exigible corresponda a docencia de Centros estatales que no existan en el Distrito universitario, el Rector de éste comunicará a la Corporación local requirente a qué órgano docente ha de dirigirse para que le sea formulada la propuesta.

Sexta. Corresponde al Ministerio de la Gobernación adecuar el Ordenamiento jurídico local a las prescripciones de la Ley General de Educación y Reglamento general de ingreso en la Función Pública.

Séptima. De persistir la praxis existente, es incuestionable que la facultad de nombrar al vocal-representante del Profesorado oficial del Estado debe corresponder al Rector de la Universidad del Distrito correspondiente.

Si «la competencia es irrenunciable y se ejercerá precisamente por los órganos administrativos que la tengan atribuida como propia», la materia «Función Pública Local» no corresponde decisoriamente más que al Ministerio de la Gobernación y a las Corporaciones locales, aunque sí pueda darse, como ocurre en otros muchos casos, una colaboración de otros Departamentos ministeriales y Entes públicos.

Nosotros, con el presente trabajo, no hemos pretendido más que prevalezca el Derecho, conscientes de nuestra función de juristas $\left({ }^{*}\right)$.

(*) Concluido este trabajo en mayo del año actual, la Orden ministerial de Educación y Ciencia de 16 de julio de 1975 ( $\propto$ B. O. E.» del 31), por la que se regula la designación de representantes del Profesorado oficial en los Tribunales calificadores de oposiciones y concursos de los funcionarios al servicio de la Administración local, dice así:

"Primero. Los Rectores de las Universidades designarán los miembros del Profesorado oficial del Estado que deban formar parte de los Tribunales calificadores de oposiciones y concursos de funcionarios de las Corporaciones locales entre los funcionarios de los Cuerpos docentes universitarios, cuando se exija para participar en los mismos títulos universitarios (bien sea de Facultad, Escuela Técnica Superior o de Escuela Universitaria), excepto en el supuesto comprendido en el artículo $235,4 .^{\circ}$, del Reglamento de Funcionarios de la Administración local, que señala la competencia del Instituto de Estudios de Administración Local para efectuar la designación del Profesorado oficial.

Segundo. En los demás casos, la designación será hecha por los Delegados provinciales del Departamento.

Tercero. Las Corporaciones locales se dirigirán, en todo caso, a los respectivos Delegados provinciales de Educación y Ciencia, que harán la designación o elevarán la petición al Rectorado competente, según proceda.

Cuarto. Queda derogada la Resolución de la Subsecretaría del Departamento de 20 de julio de 1971». 